\title{
Dữ liệu trợ giúp tính minh bạch và giải trình khoa học
}

\author{
Nguyễn Minh Hoàng \\ Ritsumeikan APU (3/10/2021)
}

Khoảng 15 năm gần đây, việc đầu tư cho khoa học ở Việt Nam gia tăng, nhờ quá trình tăng trưởng kinh tế liên tục và điều kiện tích lũy của nhà nước, xã hội, đơn vị và cả các hộ gia đình.

Cũng nhờ sự gia tăng đầu tư, và sản lượng khoa học như hệ quả của dầu tư, dần dần nhu cầu với tính minh bạch và giải trình trong kết quả khoa học cũng tăng theo. Nói ngắn gọn, xã hội, cơ quan, nhà nước và cả các cá nhân muốn có nhiều thông tin chính xác và hiểu rõ hơn về chất lượng và hiệu quả của hoạt động nghiên cứu khoa học.

Cũng vài năm trở lại đây, trong công tác nghiên cứu và quản lý khoa học cũng đã có nhiều người quan tâm, tham gia vào các mảng scientometrics và bibliometrics. Những nghiên cứu rút ra góp phần làm sáng tỏ nhiều mặt ít được chú ý của khía cạnh hiệu quả nghiên cứu, cũng như mặt trái của nó là tổn thất [1].

Tuy nhiên, bản thân việc xây dựng cơ sở dữ liệu học thuật theo yêu cầu cụ thể của công việc nghiên cứu ngành, nhóm ngành, không có sẵn dữ liệu cấu trúc, cũng rất cần thiết. Đó là lý do xuất hiện các CSDL như tác giả-tác phẩm KHXH\&NV SSHPA, hay SciMath của toán học [2].

Những CSDL đặc hữu cũng giúp thúc đẩy công việc truyền thông khoa học, trong giới và với xã hội, trở nên quen thuộc và có điểm nhấn, trọng tâm tốt hơn. Dữ liệu giúp chấm dứt việc phải truyền thông lan man bằng việc chép lại các báo cáo và đánh giá bằng lời dài lê thê, và khó rút ra các điểm kết luận quan trọng để cải thiện tình hình.

Hai trong số các ví dụ là bài báo truyền thông ngay sau khi Web of Science công bố sản phẩm thông tin khoa học định kỳ Journal Citation Reports 2019 và 2021. Bài thứ nhất đăng trên báo Khoa hoc \& Phát triển năm 2019 [3] và bài thứ hai trên Kinh tế và Dư báo năm 2021 [4]. Trong hai bài báo này, các thông tin lịch sử được lưu trữ lại, và về lâu dài sẽ có ý nghĩa đối sánh cho các số liệu khoa học tương lai. Trên thực tế, chỉ cách nhau 2 năm thôi, khả năng đối sánh đã được cho thấy rõ nét. Xin nhắc lại trích đoạn ngay ở sa-pô bài [4]: 
“[...] Cập nhật mới nhất từ dữ liệu SSHPA và JIF 2020 cho thấy, con số hơn 1.064 công bố KHXH\&NV trong năm 2020 tại Việt Nam phản ánh cả sự gia tăng về số lượng các công bố trên các tạp chí có JIF vượt trội. Số lượng các công bố trên các tạp chí có JIF > 5 đã tăng gấp 4 lần so với năm 2019. Đây là tín hiệu đáng mừng, cho thấy hiệu quả của chính sách phát triển khoa học tại Việt Nam.”

Sự so sánh còn dẫn tới những thông tin đáng chú ý hơn nữa, từ góc độ của cả nhà quản lý lẫn chủ đầu tư, cụ thể: số lượng các công bố quốc tế trên tạp chí có hệ số tác động JIF > 10 năm 2020 đã tăng hơn gấp đôi so với năm 2019. Rõ ràng là chỉ nói về phương diện đầu tư thôi, ta cũng không khó để thấy được hiệu quả của một cỗ máy vận hành vào đà. Từ 2019 tới 2021, mức gia tăng đầu tư khoa học chỉ khoảng xấp xỉ 10-15\%. Tuy nhiên, sản lượng trên các ấn phẩm có tác động cao vượt trội lại tăng ở tỷ lệ \% 3 chữ số! Sự thay đổi lớn vừa nói rõ̃ ràng cũng phản ánh quá trình chuyển biến ý thức và hành vi hướng đến sản phẩm đầu ra ở phẩm cấp quốc tế, một quá trình gian nan nhưng đã và đang mang lại kết quả rõ nét [5].

\section{Các bài báo năm 2020 đăng trên các tạp chí có JIF > 5}

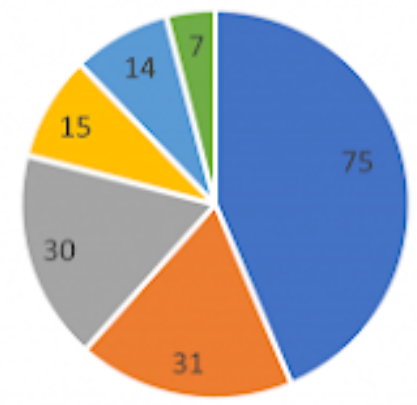

$=5-6=6-7=7-8 \quad=8-9=9-10 \quad m>10$

\section{(Hình ảnh sủ dụng lại tù bài [4])}

Với những dữ liệu rất cụ thể như thế này, trách nhiệm giải trình về hiệu quả đầu tư cho khoa học sẽ trở nên thuận lợi và đỡ tốn kém thời gian hơn nhiều. Đồng thời, nếu công việc này được tổ chức độc lập với đơn vị quản lý các nhà khoa học, thì tính khách quan và đáng tin cậy của các dữ liệu kết xuất cũng được đảm bảo. Các CSDL đặc hữu lại có thể được kết hợp với Scopus và Web of Science để kiểm tra, đối chiếu và tạo nên các tập dữ liệu kết hợp có độ tin cậy còn cao hơn nữa.

Tuy nhiên, đó là nói xuôi chiều. Ở chiều ngược lại, chúng ta cũng không khó để nhận thấy việc xây dựng và duy trì các CSDL học thuật cũng đòi hỏi nhân lực, thời gian và đầu tư hạ tầng. Việc duy trì được dài hạn là một thách thức không nhỏ. Thế nhưng, nếu có được 
hệ thống sử dụng chung và ngày càng hoàn thiện, thì chi phí sẽ giảm đi theo thời gian. Đồng thời, xét tương đối thì chi phí đó sẽ khá nhỏ so với việc phải đảm bảo trách nhiệm giải trình từ góc độ cá nhân nhà khoa học hay các tổ/nhóm, đơn vị nhỏ, không có điều kiện tổ chức dữ liệu và cũng khó tập hợp có tính hệ thống.

\section{Tài liệu tham khảo:}

[1] Vuong QH. (2018). The (ir)rational consideration of the cost of science in transition economies. Nature Human Behaviour, 2(1), 5 .

[2] Chau NB, Hoang VQ, Phuong LV, Hoa LT, Ha LM, Giang TTT, et al. (2020). The 80-year development of Vietnam mathematical research: Preliminary insights from the SciMath database on mathematicians, their works and their networks. arXiv preprint; arXiv:2011.09328.

[3] Trung T, Hạnh VT, Hạnh HP. (2019). Dấu ấn KHXH\&NV Việt Nam trên các tạp chí quốc tế có hệ số tác động cao năm 2018. Khoa hoc \& Phát triến (Jun 24). https://khoahocphattrien.vn/khoahoc/dau-an-khxhnv-viet-nam-tren-cac-tap-chi-quoc-te-co-he-sotac-dong-cao-nam-2018/201906241131457466p1c160.htm

[4] Toàn HM, Huyền NTT, Hiệp P. (2021). Journal Impact Factor 2020: Một số quan sát từ dữ liệu SSHPA. Kinh tế và Dự báo (Jul 14). https://kinhtevadubao.vn/journal-impact-factor-2020-motso-quan-sat-tu-du-lieu-sshpa-18340.html

[5] Vuong QH. (2019). Breaking barriers in publishing demands a proactive attitude. Nature Human Behaviour, 3(10), 1034. 